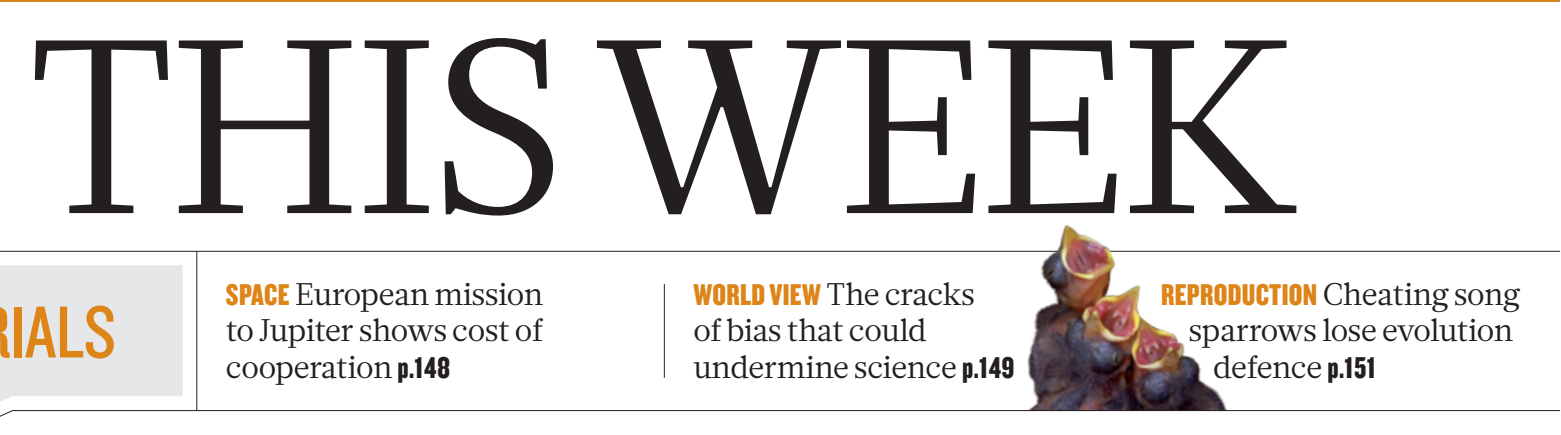

EDITORIALS cooperation $\mathbf{p . 1 4 8}$ of bias that could

undermine science $\mathbf{p . 1 4 9}$

\title{
With transparency comes trust
}

\author{
International development experts say that the Millennium Villages Project's claims of progress \\ should be interpreted with caution.
}

$\mathrm{T}$ There is an intuitive appeal to the Millennium Villages international development project - the brainchild of economist Jeffrey Sachs from Columbia University in New York that aims to help lift villages in 14 sites across Africa from poverty. The initiative takes a broad approach and aims to tackle the root causes of poverty and ill health together, unlike most aid projects, which focus on just one area.

Improvements on the ground seem impressive. In Mwandama, Malawi, crop yields shot up after the project gave farmers free fertilizer and improved varieties of maize seeds. Any food not used immediately is stored in a purpose-built warehouse and sold later in the year, earning the villagers an income. With the project's support, many villagers are now able to grow mango trees and sweet potatoes to improve food security, diversify their diet and earn extra money.

Freed from the daily struggle to fill their bellies and armed with better access to health care and education, the villagers are now setting up cooperative business ventures and investments so that they can support themselves without the project's assistance.

The villagers of Mwandama, and probably the inhabitants of the other selected villages, are clearly better off than they were six years ago, when the project started. And given the economic crisis, the project has done well to attract the funds that it has.

But prominent international development researchers and experts have taken issue with some of the project's claims of progress (see page 158) - most recently for declines in child mortality (P. M. Pronyk et al. Lancet http://dx.doi.org/10.1016/s0140-6736(12)60207-4; 2012). Their main concerns, they say, are weaknesses in the project's design and data analysis, as well as a lack of transparency over the raw data and project costs.

Michael Clemens, a development researcher at the Center for Global Development in Washington DC, has done some of the most detailed independent analyses of the project. He questions some of the key findings in the latest paper, in part because of inadequate baseline data for child mortality in the control villages.

The project started to monitor control villages only after three years had passed, when independent development researchers argued that it was necessary. So, in the absence of actual data for that period, the study asked female villagers to recall child deaths over the previous three years.

The paper does acknowledge that this method is unreliable and can underestimate child deaths. So how reliable are comparisons made against such data? Clemens says that alarm bells should have started ringing when the verbal reports suggested that the child death rate in the control villages rose over the study period, contradicting continent-wide trends of falling child mortality. This would have resulted in an overestimation of the difference in child mortality between the two sites, Clemens argues.

Furthermore, he says that the study's statistical analysis fails to show that the annual rate of decline in the project villages is triple that of national rural trends, as claimed. And, he says, the data set used for national child mortality was a misleading comparison because it includes the period 2000-06, before the villages project started, when the national child death rate was falling more slowly than in 2006-10. This, he says, made national rural trends seem lower than they actually are, thereby inflating the improvements in the project villages.

Nature put these criticisms to the organizers of the Millennium Villages Project and received lengthy written and verbal responses. Not all
"The project's approach has potential, but little can be said for sure about its true impact." of these helped to clarify the situation. When asked, for example, why the claimed improvements in child mortality were placed in such a prominent position in the paper despite being statistically insignificant, the organizers replied that they were there for "illustrative" purposes.

The Millennium Villages Project has problems beyond the analysis of data. The organizers have been reluctant to publish a full breakdown of costs - making it impossible for those not privy to the information to verify their cost-benefit analysis, which is crucial in development policy because spending is under great scrutiny. The project also seems to lack a coherent policy on when and how it will make data available to independent researchers.

Clemens and others are right to ask that the project make this information available. Greater transparency is essential to build trust and credibility. The project's approach has potential, but little can be said for sure yet about its true impact. The latest initiative of the Millennium Villages Project, in Ghana and funded by the UK government, is a welcome step in the right direction. It builds in independent scrutiny from the start, and has been open and transparent about its costs. All future projects should follow this model. .

\section{Misplaced protest}

\section{Rothamsted's genetically engineered wheat} should be allowed to grow.

$\mathrm{P}$ lant scientists at Rothamsted Research, a complex of buildings and fields in Hertfordshire, UK, that prides itself on being the longest-running agricultural research station in the world, have spent years preparing for their latest experiment - which will attempt to prove the usefulness of a genetically modified (GM) wheat that emits an aphid alarm pheromone, potentially reducing aphid infestation.

Yet instead of looking forward to watching their crop grow, the Rothamsted scientists are nervously counting the days until 27 May, 
when protesters against GM crops have promised to turn up in force and destroy the experimental plots.

The protest group, it must be acknowledged, has a great name Take the Flour Back. And it no doubt believes that it has the sympathy of the public. The reputation of GM crops and food in Britain, and in much of mainland Europe, has yet to recover from the battering it took in the late 1990s. In Germany, the routine destruction of crops by protesters has meant that scientists there simply don't bother to conduct GM experiments any more.

The Rothamsted scientists have also attempted to win over the public, with a media campaign that explains what they are trying to do and why. After the protesters announced their plans to "decontaminate" the research site, the scientists tried to engage with their opponents, and pleaded with them to "reconsider before it is too late, and before years of work to which we have devoted our lives are destroyed forever". The researchers say that in this case they are the true environmentalists. The modified crop, if it works, would lower the demand for environmentally damaging insecticides.

As Nature went to press, the stalemate continued. The GM crop at Rothamsted remains, but so does the intention of the protesters to destroy it.

There are very real consequences to this kind of protest. German chemical giant BASF this year announced that it would move its transgenic plant operations from Europe to the United States, in part because of the perception of continuing widespread opposition to GM crops in Europe. And although farmers in other parts of the world have taken to GM crops with gusto, Europe, with some exceptions, misses out. Evidence suggests that it is missing a lot. The adoption of herbicide-resistant oilseed rape has reduced the use of herbicides by farmers in North America, and also reduced tillage, which has its own environmental benefits. The adoption of pest-resistant GM cotton has lowered the use of pesticides. Nevertheless, the reasons for the hostility towards genetic modification in Europe are clear. Justifiable unease over the way in which GM-led business models would hand entire food chains to large agrochemical companies found a popular proxy in less-realistic concerns over the possible health impacts of the new technology.

But with the world's population now at 7 billion and counting, the
"To destroy experiments before the outstanding questions can be answered is more than local vandalism, it is recklessness on a global scale." rejection of genetic modification of crops on such spurious scientific grounds now threatens the environment it claims to protect. To feed a population likely to top 9 billion in 2100 , we are going to need to change the way we grow our food. Harking back to oldfashioned methods and talking up organic farming will not do it. Genetic modification alone will not do it, but it could be a crucial tool and one that it is foolish to oppose on sentimental or ideological grounds.

This will not convince diehard opponents, of course, just as pleas for the value of scientific research failed to sway the criminal faction of the animal-rights movement. But, just as it proved with animal rights, it is far from clear that GM protesters, however many turn up at Rothamsted in a fortnight, truly attract public support.

GM crops could significantly reduce the use of pesticides, herbicides and fertilizers, and provide greater tolerance to a more extreme climate. True, we are still in the early stages of this technology. And there are some legitimate concerns, such as possible leakage of GM material into the local environment. But to destroy experiments such as the one at Rothamsted before the outstanding questions can be answered is more than local vandalism, it is recklessness on a global scale.

\section{Price of freedom}

\section{The latest mission to Jupiter highlights the benefits and pitfalls of collaboration.}

$\mathrm{I}$ $\mathrm{t}$ is a long trip to the outer reaches of the Solar System. Planetary scientists who are eager to explore Jupiter and the planets beyond tend to plan their experiments not in terms of years, but generations. And so it is with some rejoicing, and also relief, that they have another mission on the books.

Last week, the European Space Agency (ESA) announced that it had selected the Jupiter Icy moons Explorer, or JUICE, a solar-powered behemoth that, at 4.8 tonnes, would be the heaviest interplanetary probe ever flown by Europe. It would launch in 2022 and arrive at Jupiter almost eight years later. After a few flybys of Jupiter's moons Callisto and Europa, in 2032 the probe would settle into orbit around its primary target, the moon Ganymede, for at least a year of science. Ganymede's main mystery is its enigmatic magnetic field, the only moon in the Solar System to have one. But, like Europa, Ganymede also has a subsurface ocean although one that is less enticing to astrobiologists because it is likely to be isolated, sandwiched between thick layers of ice that prevent interesting chemical interactions with the surface and the deep rocky mantle.

Still, JUICE came top in a competition that sent two other prospective European missions packing. One was an X-ray telescope that would have imaged objects such as black holes with greater precision and sensitivity than ever before. Another was a set of satellites that, flying in formation, would have sensed tiny ripples in the fabric of space caused by violent events such as black-hole mergers - thereby opening up a whole new field: observational gravitational-wave astronomy.

Neither mission was a dud scientifically; quite the opposite. The gravitational-wave mission, in particular, is viewed as representing a scientific revolution in the making. These missions failed in the competition because they were expensive, and were likely to bust ESA's budget of $€ 1$ billion (US $\$ 1.3$ billion). And the reason ESA could not afford them was because both were originally designed as joint missions with the United States. When NASA pulled out, each mission tried to reduce its scope and lower its price tag, but that proved too difficult.

JUICE was also once married to a NASA mission, but in a more modern arrangement. The ESA mission would have had its own satellite and rocket launcher, as would NASA, which would have sent an orbiter devoted to studying Europa. When the budgetary rug was pulled out from under NASA's Europa orbiter, JUICE was in much better shape, politically and financially.

The lessons here would seem to be perverse: eschew tight collaborations and you will be rewarded for your independence. Avoid working with foreign agencies and you will be better off in the long run.

That might be true, but only from the perspective of a scientist interested in Ganymede - and only Ganymede. Without NASA involvement, plenty of Europan science has been lost. And had the two missions launched as a loose partnership, there would have been several ways in which the sum of the two missions was greater than its parts. For example, tracking the magnetosphere of the Jovian system using two probes makes a far better map than using just one.

The bigger point, however, is that the frontiers of science in many fields are reaching the stage - or price tag — at which no single country can go it alone. Just ask scientists who worked on completing the Human Genome Project, or building the Large Hadron Collider near Geneva, Switzerland. Of late, space scientists at NASA and ESA have no such project to hold up as an example. In addition to the X-ray and gravitational-wave observatories, other transatlantic partnerships have $\checkmark$ NATURE.COM To comment online, click on Editorials at: go.nature.com/xhunqv evaporated, including ones to study dark energy and to return samples from Mars. If a mission to the king of the planets is a cause for rejoicing, then the fact that it is so singular may be a cause for alarm. 